\title{
CORRECTION
}

\section{Correction to: A review of tennis racket performance parameters}

\author{
Tom Allen $^{1,2} \cdot$ Simon Choppin ${ }^{1} \cdot$ Duane Knudson $^{3}$
}

Published online: 12 November 2020

(c) International Sports Engineering Association 2020

\section{Correction to: Sports Eng (2016) 19:1-11}

https://doi.org/10.1007/s12283-014-0167-x

In the original version of the article, Eq. (2) was published incorrectly and the correct Eq. (2) is

$M_{e e}(a, b)=\frac{I_{p} \cdot M_{e}(b)}{I_{p}+M_{e}(b) a^{2}}$

These corrections do not affect any of the results or other expressions reported in the paper.

Publisher's Note Springer Nature remains neutral with regard to jurisdictional claims in published maps and institutional affiliations.

The original article can be found online at https://doi.org/10.1007/ s12283-014-0167-x.

Tom Allen

t.allen@shu.ac.uk

1 Centre for Sports Engineering Research, Sheffield Hallam University, Sheffield, UK

2 Department of Engineering and Maths, Sheffield Hallam University, Sheffield, UK

3 Department of Health and Human Performance, Texas State University, San Marcos, USA 